\title{
Efficiency of stabilization of slag suspensions by polycarboxylate
}

\author{
Svetlana Samchenko ${ }^{1}$, Irina Kozlova ${ }^{1,{ }^{*}}$, Olga Zemskova ${ }^{1}$, Denis Potaev $^{1}$ and Dana \\ Tsakhilova ${ }^{1}$ \\ ${ }^{1}$ Moscow State University of Civil Engineering, Yaroslavskoe shosse, 26, Moscow, 129337, Russia
}

\begin{abstract}
The paper describes the method of stabilization of slag suspensions prepared on the basis of finely ground slag (FGS) with a predominant particle size of 1-7 $\mu \mathrm{m}$, a plasticizer based on polycarboxylate (polycarboxylate). In suspension, FGS particles form two types of micelles with negative and positive surface charges. It has been established that stabilization with polycarboxylate, which is an anionic long-chain surfactant, affects slag particles with a positive surface charge. The formation of strong and elastic gel-like films on the surface of FGS leads to an increase in the structural and mechanical factor of aggregative stability of slag suspensions. Thus, the stabilization of slag particles by polycarboxylate is ensured by electrostatic, structural and mechanical factors of aggregative stability. It was established experimentally that the introduction of polycarboxylate into the aqueous dispersion medium increases the aggregative and sedimentation stability of slag suspensions. In the first period of particle sedimentation, on average, stability of slag suspensions is increased by 36 times, in the second period - 19 times, in the third period - 4 times. To ensure stability of slag suspensions, the protective number and the optimal concentration of the polycarboxylate are determined. The protective number of the suspension was $0,016 \mathrm{~g} / \mathrm{l}$; the optimal concentration of polycarboxylate - $4 \mathrm{~g} / \mathrm{l}$.
\end{abstract}

\section{Introduction}

Expanding the needs of the construction industry requires the production of new building materials, preferably using non-deficient raw materials. The relevant task is to use the waste of metallurgical enterprises as secondary resources in the production of building materials. Such waste includes blast furnace granulated slag. A lot of work has been devoted to its use in the production of cement, concrete, and composite binders [1-7]. Slagbased cement products have several advantages over non-additive Portland cement. These include low exotherm, increased corrosion and heat resistance, workability of the concrete mix, protection of finished structures from weathering and cracking [8-12]. These characteristics increase the durability of products and constructions. However, the use of slag cements in the construction industry is limited due to the slow set of strength in the initial periods of hardening. To solve this problem, we proposed to use slag in the form of a

\footnotetext{
*Corresponding author:iv.kozlova@mail.ru
} 
finely ground component in the composition of multicomponent cements [13-15]. An increase in the strength of cements with the addition of finely ground slag (FGS) in the initial periods of hardening by an average of $50 \%$ was observed, but the standard deviation of the strength characteristics was 6-7\%, indicating uneven distribution of the slag component in the cement system. To ensure uniform distribution of slag particles in the volume of the cement matrix, it is proposed to introduce FGS as a suspension into the cement instead of mixing water [16-18]. The papers [19-25] carried out studies on the establishment of aggregative and sedimentation stability of dispersions of various substances of the nanoscale series: carbon nanotubes, europium oxohydroxide hydrosol, $\gamma$ $\mathrm{Al}_{2} \mathrm{O}_{3}$ sol, etc. The results of the studies showed that the establishment of aggregative and sedimentation stability of dispersions and the use of methods of homogenization and stabilization contribute to the uniform distribution of particles in the volume of the cement matrix and the production of products with enhanced performance properties. As a result, the goals and objectives of the present study were defined, which are to choose a stabilizer for the slag suspension and to assess its effect on the stabilization of slag particles in the suspension.

\section{Experimental}

In our study, granulated blast furnace slag was used as the object of study, which was subjected to grinding in the LHL-1 laboratory jet mill with the restriction of the upper limits of grinding to a particle size of $20 \mu \mathrm{m}$. Characteristics of granulated blast furnace slag, including chemical and phase compositions, are listed in Table 1. The particle size after grinding in a jet mill was determined on the Mastersizer 3000 laser diffraction particle size analyzer. The distribution curve of the slag particles by fractions is shown in Fig. 1, the particle size distribution of finely ground slag is presented in Table 2 it was found that the used slag belongs to the main, as it has $\mathrm{a}_{\mathrm{o}}>1$. Based on the chemical composition of the slag and the calculated modulus of basicity, the presence of basic calcium orthosilicates, predominantly $\mathrm{Ca}_{2} \mathrm{SiO}_{4}$, is assumed in FGS.

Table 1. Characteristics of granulated blast furnace slag.

\begin{tabular}{|c|c|c|c|c|c|c|}
\hline $\begin{array}{c}\text { Chemical } \\
\text { composition, } \\
\%\end{array}$ & $\mathrm{CaO}$ & $\mathrm{SiO}_{2}$ & $\mathrm{Al}_{2} \mathrm{O}_{3}$ & $\mathrm{MgO}$ & $\mathrm{Fe}_{2} \mathrm{O}_{3}+\mathrm{FeO}$ & others \\
\cline { 2 - 7 } & 45.40 & 38.20 & 8.10 & 3.20 & 0.80 & 4.30 \\
\hline $\begin{array}{c}\text { Phase } \\
\text { composition, } \\
\%\end{array}$ & \multicolumn{3}{|c|}{ glass } & \multicolumn{3}{|c|}{ crystalline phase } \\
\cline { 2 - 6 } & 93.20 & \multicolumn{3}{c|}{60} \\
\hline
\end{tabular}

Table 2. FGS particle size distribution.

\begin{tabular}{|c|c|}
\hline Particle size, $\mu \mathrm{m}$ & Content of fractions, wt.\% \\
\hline $0-1$ & 9 \\
\hline $1-5$ & 37 \\
\hline $5-7$ & 17 \\
\hline $7-10$ & 14 \\
\hline $10-15$ & 10 \\
\hline $15-20$ & 8 \\
\hline $20-30$ & 5 \\
\hline
\end{tabular}




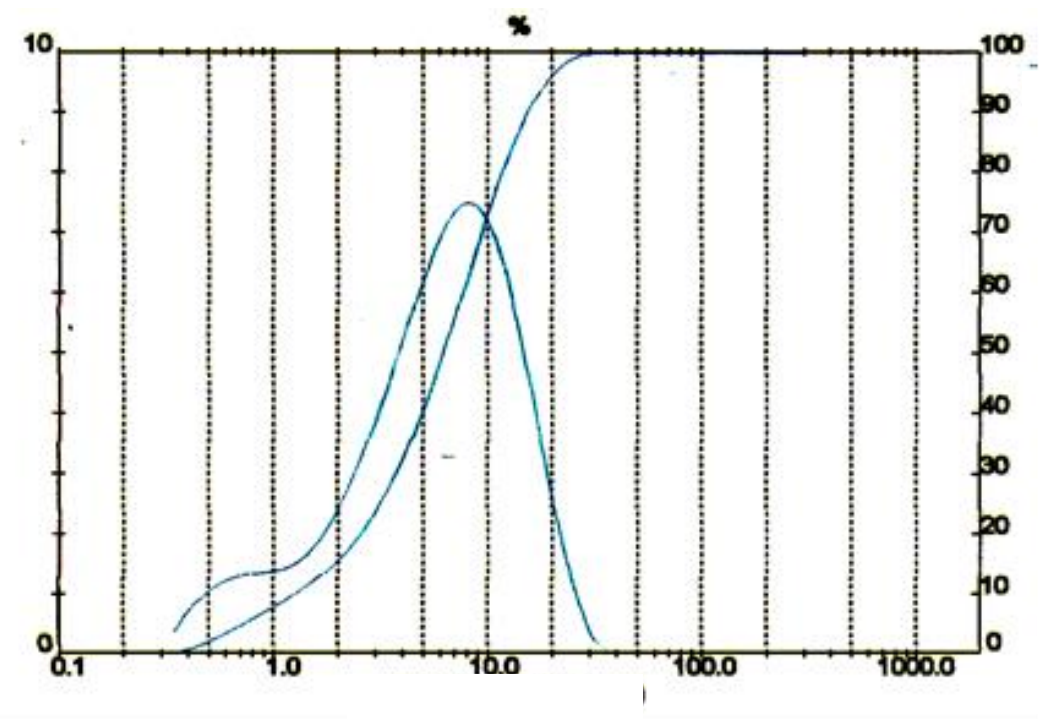

Fig. 1. The distribution curve of the FGS particles by fractions.

When calculating the modulus of basicity by the formula:

$$
M_{o}=\frac{\mathrm{CaO}+\mathrm{MgO}}{\mathrm{SiO}_{2}+\mathrm{Al}_{2} \mathrm{O}_{3}}=1,1
$$

It follows from Table 2 that FGS obtained in a laboratory jet mill, have a predominant particle size of $1-7 \mu \mathrm{m}$. This size of FGS allows it to be attributed to submicron particles, which, like nanoparticles, are prone to aggregation. The introduction of FGS into the cement in the form of a dry powder does not allow obtaining stable results of physical and mechanical tests. In this regard, slag suspensions based on FGS were obtained, and studies were conducted to establish the aggregative and sedimentation stability of suspensions in an aqueous dispersion medium [17].

It was established that the process of sedimentation of FGS is divided into 3 periods, and the particles most quickly settle in the first period of sedimentation. To increase the stability, especially in the first sedimentation period, a plasticizer on a polycarboxylate basis with the general formula $\mathrm{R}-\mathrm{CH}-\mathrm{COONa}$ was introduced into the slag suspensions.

\section{Evaluation}

In an aqueous dispersion medium, FGS form two types of micelles with negative and positive nuclear charge. Initially, the FGS surface is negatively charged due to the formation of reaction products from groups of silicic acid ions of different basicity. As the hydration reaction proceeds, the active centers in the areas of the surface layer of the slag are saturated with $\mathrm{Ca}^{2+}$ ions and are charged positively $[16,17]$. To stabilize the positively charged slag particles, a plasticizer on a polycarboxylate basis (polycarboxylate), which is an anionic long-chain surfactant, was introduced into the aqueous suspension.

To establish the plasticizer concentration, which ensures the stability of the slag suspension, the protective number of the suspension was determined experimentally. For the slag suspension stabilized by polycarboxylate, the protective number was $0.016 \mathrm{~g} / \mathrm{l}$, the optimal concentration of polycarboxylate was $4 \mathrm{~g} / \mathrm{l}$ at the concentration of slag in suspension $50 \mathrm{~g} / \mathrm{l}$ (Table 3). The methodology of this experiment is presented in [20-21]. 
Table 3. The results of studies of the aggregative stability of slag suspensions stabilized by polycarboxylate.

\begin{tabular}{|c|c|c|c|c|c|c|c|c|c|c|}
\hline \multirow{2}{*}{ Name of indicator } & \multicolumn{10}{|c|}{ № of test } \\
\cline { 2 - 12 } & 1 & 2 & 3 & 4 & 5 & 6 & 7 & 8 & 9 & 10 \\
\hline $\begin{array}{c}\text { Concentration of } \\
\text { FGS in } \\
\text { suspension, g/l }\end{array}$ & 50 & 50 & 50 & 50 & 50 & 50 & 50 & 50 & 50 & 50 \\
\hline $\begin{array}{c}\text { Concentration of } \\
\text { stabilizer, g/l }\end{array}$ & 1 & 2 & 3 & 4 & 5 & 6 & 7 & 8 & 9 & 10 \\
\hline $\begin{array}{c}\text { Protective number } \\
\text { of suspension, * } \\
10^{-3} \text { g/l }\end{array}$ & 1 & 4 & 9 & 16 & 25 & 36 & 49 & 64 & 81 & 100 \\
\hline $\begin{array}{c}\text { End time of } \\
\text { complete slag } \\
\text { sedimintation, h- } \\
\text { min }\end{array}$ & $3-30$ & $5-00$ & $6-30$ & $7-10$ & $7-30$ & $7-30$ & $7-40$ & $7-40$ & $7-50$ & $7-50$ \\
\hline
\end{tabular}

The efficiency of stabilization of slag suspensions with polycarboxylate is confirmed by the results presented in Table 4. It follows from the above data that with the introduction of polycarboxylate into the aqueous dispersion medium, the aggregative and sedimentation stability of the slag suspensions increases. In the first period, on average, stability is increased by 36 times, in the second period - 19 times, in the third period - 4 times.

Table 4. Time and sedimentation rate of FGS particles in aqueous and aqueous-polycarboxylate dispersion media.

\begin{tabular}{|c|c|c|c|c|c|c|c|}
\hline \multirow{2}{*}{$\begin{array}{l}\text { Experi- } \\
\text { mental } \\
\text { condi- } \\
\text { tions* }\end{array}$} & \multirow{2}{*}{$\begin{array}{c}\text { Con- } \\
\text { centra- } \\
\text { tion of } \\
\text { FGS, } \\
\text { g/l }\end{array}$} & \multicolumn{6}{|c|}{ Particle sedimentation period } \\
\hline & & $\begin{array}{c}\text { Sedimentation } \\
\text { time of particles } \\
\text { h: min: s }\end{array}$ & $\begin{array}{c}\text { Particle } \\
\text { sedimentation } \\
\text { rate, } 10^{-5} \mathrm{~m} / \mathrm{s}\end{array}$ & $\begin{array}{c}\text { Sedimentation } \\
\text { time of particles } \\
\text { h: min: s }\end{array}$ & $\begin{array}{c}\text { Particle } \\
\text { sedimentation } \\
\text { rate, } 10^{-5} \mathrm{~m} / \mathrm{s}\end{array}$ & $\begin{array}{c}\text { Sedimentation } \\
\text { time of particles } \\
\text { h: min: s }\end{array}$ & $\begin{array}{c}\text { Particle } \\
\text { sedimentation } \\
\text { rate, } 10^{-5} \mathrm{~m} / \mathrm{s}\end{array}$ \\
\hline \multirow{2}{*}{1} & 10 & 00:06:00 & 43.30 & $00: 19: 00$ & 13.40 & $01: 55: 00$ & 2.32 \\
\hline & 50 & $00: 02: 10$ & 145.00 & $00: 12: 00$ & 23.80 & $01: 45: 00$ & 2.43 \\
\hline \multirow[b]{2}{*}{2} & 10 & 03:10:00 & 13.60 & 05:00:00 & 8.70 & 08:20:00 & 5.23 \\
\hline & 30 & 02:40:00 & 15.30 & 04:30:00 & 8.80 & 08:10:00 & 5.30 \\
\hline \multirow[t]{2}{*}{$\mathrm{V}_{1} / \mathrm{V}_{2}$} & 30 & \multicolumn{2}{|c|}{38.4} & \multicolumn{2}{|c|}{27.0} & \multicolumn{2}{|c|}{4.5} \\
\hline & 50 & \multicolumn{2}{|c|}{64.4} & \multicolumn{2}{|c|}{21.8} & \multicolumn{2}{|c|}{4.2} \\
\hline
\end{tabular}

*1 - without polycarboxylate; 2 - with polycarboxylate

The interaction of FGS with polycarboxylate occurs by the equation:

$$
\begin{array}{cc}
\mathrm{Ca}_{2} \mathrm{SiO}_{4}+\mathrm{R}-\mathrm{CH}-\mathrm{COONa}+\mathrm{HOH} \\
\mathbf{I} & \mathrm{CaHSiO}_{4}-\mathrm{OCO}-\mathrm{CH}-\mathrm{R}+\mathrm{NaOH} \\
\mathrm{R}^{\prime} & \mathbf{I} \\
& \mathrm{R}^{\prime}
\end{array}
$$

where R- nonpolar radical of polycarboxylate main chain; R'- non-polar radical of polycarboxylate side chain.

In an aqueous dispersion medium, polycarboxylates dissociate to form surface-active anions - functional carboxyl groups $\mathrm{R}-\mathrm{CH}-\mathrm{COO}^{-}$. 
In the surface layer of the slag particles with a positive surface charge, the process of adsorption begins, accompanied by the fixation of functional groups of the polycarboxylate. The slag surface is negatively charged, and the $\mathrm{H}^{+}$ions are in the diffuse layer. An electric double layer is formed with the participation of polycarboxylate. The mechanism of stabilization of FGS by polycarboxylate is shown in Figure 2. Figure 3 shows the structure of a slag micelle stabilized by polycarboxylate.
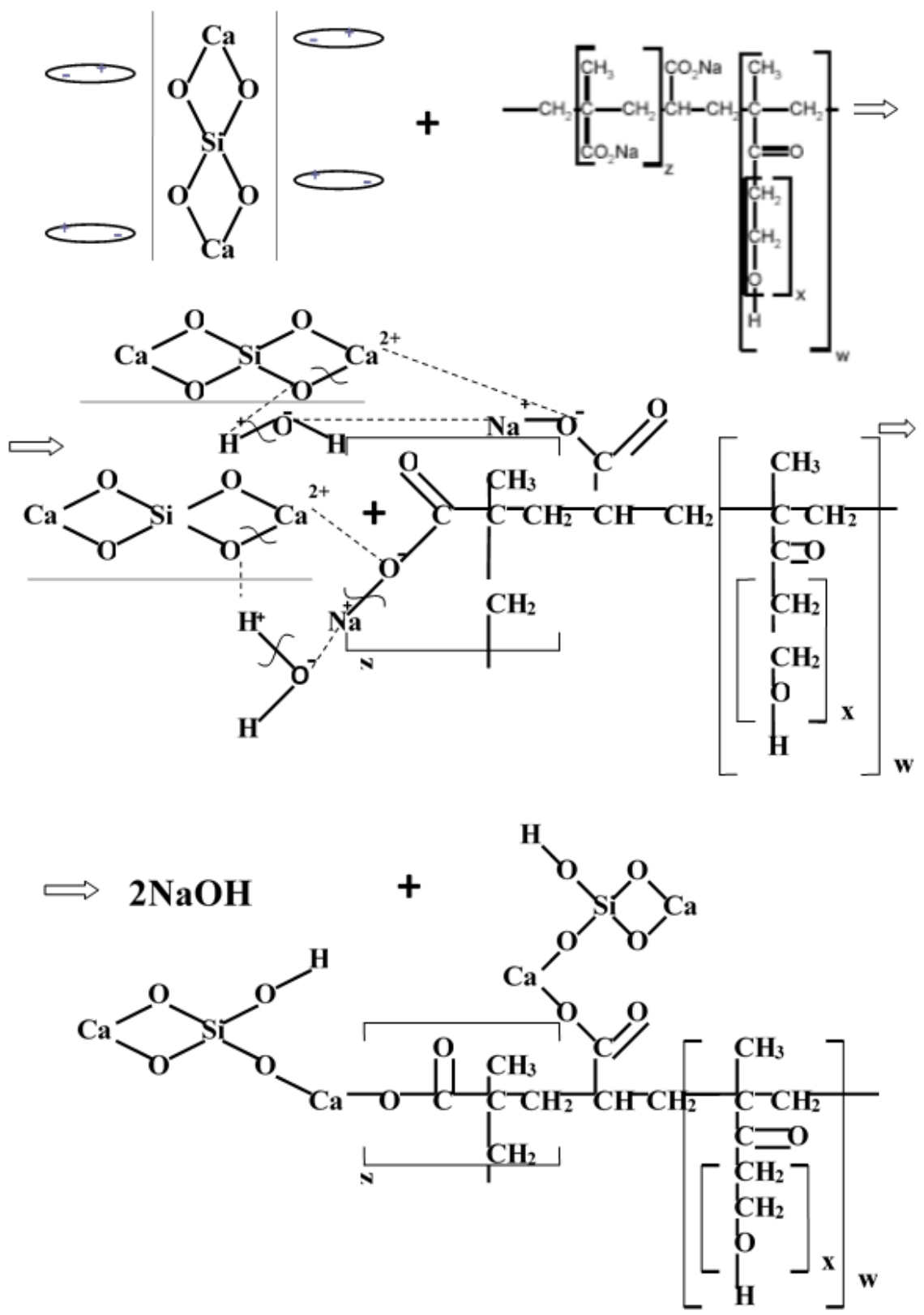

Fig. 2. The mechanism of stabilization of FGS by polycarboxylate. 


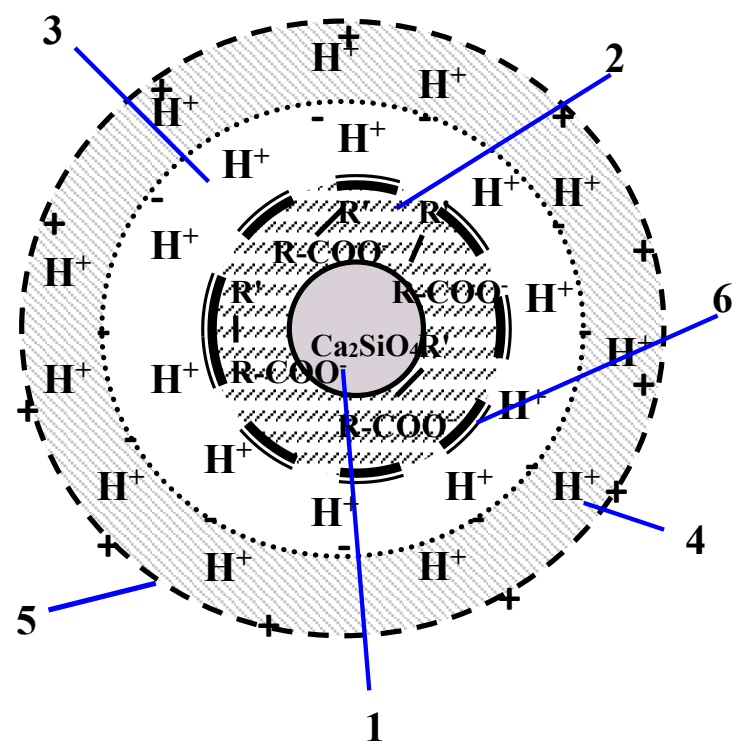

Fig. 3. The structure of FGS micelle stabilized by polycarboxylate: 1 - FGS aggregate $\left(\mathrm{Ca}_{2} \mathrm{SiO}_{4}\right) ; 2$ layer of potential-determining ions; 3 - counterions of the dense part of the electric double layer; 4 diffusion layer counterions; 5 - FGS micelle; 6 - gel-like film of radicals of the main and side chains $\mathrm{R}-\mathrm{CH}(\mathrm{COO}) \square-\mathrm{R}^{\prime}$.

In [16-17], it was established that the presence of an electrical double layer in FGS particles causes an aggregative and sedimentation stability of the slag suspension due to the electrostatic stability factor. With the introduction of polycarboxylate in the slag suspension, the formation of the adsorption layer near the surface of the slag particles is affected by its main hydrocarbon chain in the direction from the slag particles and the side hydrocarbon chain, creating an additional spatial (steric) effect of stability. The same radicals form strong and elastic gel-like films on the surface of FGS particles (Fig. 3 (6)), strengthening the structural and mechanical factor of aggregative stability. Thus, the introduction of polycarboxylate in the slag suspension provides stabilization of the slag particles due to electrostatic, structural and mechanical factors of aggregative stability.

\section{Conclusions}

1. Introduction of polycarboxylate into the aqueous dispersion medium increases the aggregative and sedimentation stability of slag suspensions. In the first period of sedimentation of particles, on average, stability of the slag suspension is increased by 36 times, in the second period - 19 times, in the third period - 4 times.

2. To ensure stability of slag suspensions, the protective number and the optimal concentration of the polycarboxylate are determined. The protective number of the suspension was $0,016 \mathrm{~g} / \mathrm{l}$; the optimal concentration of polycarboxylate $-4 \mathrm{~g} / \mathrm{l}$.

3. It has been established that the stabilization of slag particles in an aqueous suspension in the presence of polycarboxylate is provided by electrostatic, structural and mechanical factors of aggregative stability. The presence of a double electric layer in FGS particles causes aggregative and sedimentation stability of the slag suspension due to the electrostatic stability factor. The formation of an adsorption layer at the surface 
of the slag particles is influenced by the polycarboxylate radicals. Its main hydrocarbon chain provides stability in the direction from the slag particles; the side hydrocarbon chain creates an additional spatial (steric) effect of stability. In the complex, polycarboxylate radicals form strong and elastic gel-like films on the surface of FGS particles and enhance the structural and mechanical factor of the aggregative stability of slag suspensions.

\section{References}

1. N.A. Shapovalov, L.H. Zagorodnyuk, I.V. Tikunova, A.Y. Shchekina, A.V. Shkarin, Fundamental'nye issledovaniya 1-1, 167-172 (2013)

2. F.L. Kapustin, D.V. Ragozin, A.A. Kuznecov, I.S. Semerikov, A.F. Kapustin, Vestnik YUzhno-Ural'skogo gosudarstvennogo universiteta, Stroitel'stvo i arhitektura 15(191), 22-24.3 (2010)

3. L.H. Zagorodnyuk, L.D. Shahova, S.V. Yakovlev, Beton i zhelezobeton 2, 18-20 (2010)

4. V.S. Lesovik, M.S. Ageeva, A.V. Ivanov, Vestnik Belgorodskogo gosudarstvennogo tekhnologicheskogo universiteta im. V.G. SHuhova 3, 29-32 (2011)

5. I.L. Tsipursky, A.A. Kokonova, E.D. Danilova, I.V. Kovchenko, M.I. Rudenko, Russian journal of transport engineering 5(1), 1-8 (2018) DOI: 10.15862/18SATS118

6. J. Shang, J.-G. Dai, T.-J. Zhao, S.-Y. Guo, P. Zhang, B. Mu, Journal of Cleaner Production 203, 746-756 (2018) DOI: 10.1016/j.jclepro.2018.08.255

7. G.I. Ovcharenko, A.V. Viktorov, M.P. Veselkova, Stroitel'stvo 9(681), 25-30 (2015)

8. V.V. Mihajlov, V.A. Popova, M.I. Bejlina, Beton i zhelezobeton 2, 13-14 (1987)

9. B.Y. Trofimov, L.Y. Kramar, K.V. Shuldyakov, Stroitel'nye materialy 9, 96-101 (2013)

10. T.M. Petrova, O.M. Smirnova, S.T. Frolov, Vestnik grazhdanskih inzhenerov 2, 118 123 (2011)

11. A. Altun, S. Akpinar, H. Pala, Ogneupory i tekhnicheskaya keramika 11-12, 63-66 (2009)

12. G.S. Royak, I.V. Granovskaya, Cement i ego primenenie 3, 104-106 (2011)

13. A.G. Ptichnikov, ALITinform: Cement. Beton. Suhie smesi 2-3(39), 52-67 (2015)

14. S.V. Samchenko, O.V. Zemskova, I.V. Kozlova, Tekhnika i tekhnologiya silikatov 23(2), 19-23 (2016)

15. I.V. Kozlova, Uspekhi sovremennoj nauki 5(4), 7-11 (2017)

16. I.V. Kozlova, K.V. Nechaev, Mezhdunarodnyj zhurnal po vyazhushchim, keramike, steklu i ehmalyam 25(4), 109-114 (2018)

17. S. Samchenko, I. Kozlova, O. Zemskova, E. Baskakova, MATEC Web of Conferences 265, 01017 (2019) GCCDOI:10.1051/matecconf/201926501017

18. S. Samchenko, O. Zemskova, I. Kozlova, MATEC Web of Conferences 106, 03017 (2017) DOI: 10.1051/matecconf/20171060 SPbWOSCE-2016 3017

19. S. Samchenko, I. Kozlova, O. Zemskova International Multidisciplinary Scientific GeoConference Surveying Geology and Mining. Ecology Management, SGEM 18(6.3), 437-444 (2018) DOI: 10.5593/sgem2018/6.3/S26.057

20. S. Samchenko, O. Zemskova, I. Kozlova, Russian Journal of Applied Chemistry 87(12), 1872 - 1876 (2014) 
21. S.V. Samchenko, Cement-Wapno-Beton XX/LXXXII(5), 322-327 (2015)

22. S.V. Samchenko, O.V. Zemskova, I.V. Kozlova, Tekhnika i tekhnologiya silikatov 21(3), $14-18$ (2014)

23. S. Samchenko, I. Kozlova, O. Zemskova, MATEC Web of Conferences 193, 03050 (2018) DOI: 10.1051/matecconf/201819303050.

24. E.A. Zaharychev, M.A. Kabina, E.N. Razov, L.L. Semenycheva, Kolloidnyj zhurnal 78(5), 556-561 (2016)

25. A.V. Malova, A.S. Grodskij, I.A. Belova, Kolloidnyj zhurnal 78(4), 450-458 (2016) 